\title{
Anopheles subpictus carry human malaria parasites in an urban area of Western India and may facilitate perennial malaria transmission
}

Ashwani Kumar ${ }^{1 *}$, Rajeshwari Hosmani ${ }^{1}$, Shivaji Jadhav ${ }^{1}$, Trelita de Sousa ${ }^{1}$, Ajeet Mohanty ${ }^{1}$, Milind Naik Adarsh Shettigar' ${ }^{1}$, Satyajit Kale', Neena Valecha², Laura Chery ${ }^{3}$ and Pradipsinh K. Rathod ${ }^{3}$

\begin{abstract}
Background: India contributes 1.5-2 million annual confirmed cases of malaria. Since both parasites and vectors are evolving rapidly, updated information on parasite prevalence in mosquitoes is important for vector management and disease control. Possible new vector-parasite interactions in Goa, India were tested.

Methods: A total of 1036 CDC traps were placed at four malaria endemic foci in Goa, India from May 2013 to April 2015. These captured 23,782 mosquitoes, of which there were 1375 female anopheline specimens with ten species identified using morphological keys. Mosquito DNA was analysed for human and bovine blood as well as for Plasmodium falciparum and Plasmodium vivax infection.

Results: Human host feeding was confirmed in Anopheles stephensi (30 \%), Anopheles subpictus (27\%), Anopheles jamesii (22\%), Anopheles annularis (26\%), and Anopheles nigerrimus (16\%). In contrast, Anopheles vagus, Anopheles barbirostris, Anopheles tessellates, Anopheles umbrosus and Anopheles karwari specimens were negative for human blood. Importantly, An. subpictus, which was considered a non-vector in Goa and Western India, was found to be a dominant vector in terms of both total number of mosquitoes collected as well as Plasmodium carriage. Plasmodium infections were detected in 14 An. subpictus (2.8\%), while the traditional vector, An. stephensi, showed seven total infections, two of which were in the salivary glands. Of the 14 An. subpictus infections, nested PCR demonstrated three Plasmodium infections in the salivary glands: one P. vivax and two mixed infections of $P$. falciparum and $P$. vivax. In addition, ten gut infections (one P. vivax, six P. falciparum and three mixed infections) were seen in An. subpictus. Longitudinal mosquito collections pointed to a bimodal annual appearance of An. subpictus to maintain a perennial malaria transmission cycle of both P. vivax and P. falciparum in Goa.
\end{abstract}

Keywords: Malaria, Goa, New vector, Salivary glands, Plasmodium, Anopheles subpictus

\section{Background}

India contributes significantly to the total malaria burden in the world with about 1.5-2 million confirmed malaria cases and annual death estimates ranging from 15,000 to $95,000[1,2]$. The epidemiology of malaria in India is complex due to the geo-ecological diversity of

\footnotetext{
*Correspondence: ashwani07@gmail.com

${ }^{1}$ National Institute of Malaria Research, Field Unit, Campal, Goa, India Full list of author information is available at the end of the article
}

the country, multi-ethnicity of human hosts, wide distribution of different anopheline species, and extensive human mobility within the country and from outside [1]. Historically, the 1950s malaria eradication programme in India, led by World Health Organization (WHO) and focused on vector control using indoor residual insecticide DDT, was considered a success. Malaria incidence in humans decreased from about 75 million in 1947 to less than 100,000 in 1964 [1]. Malaria was then thought to be 
on the verge of eradication in India, but it re-emerged in 1976 [3].

Areas with unstable malaria present an important opportunity to re-examine human-parasite-vector interactions that contribute to the transmission of malaria. Traditionally, there are six recognized primary vectors of malaria in India, viz., Anopheles culicifacies, Anopheles stephensi, Anopheles dirus (Anopheles baimaii), Anopheles fluviatilis, Anopheles minimus and Anopheles sundaicus. Vectors of secondary importance are Anopheles annularis, Anopheles varuna, Anopheles jeyporiensis and Anopheles philippinensis [4]. Anopheles stephensi has been incriminated repeatedly and strongly in different parts of India. The species is capable of transmitting malaria at very low densities and is an important urban malaria vector in the country [4].

In the coastal belt of Goa, following a 1986 malaria outbreak in urban Panaji, An. stephensi was extensively studied for its role as the primary vector in malaria transmission in terms of both its resting and biting behaviour and its breeding habits [5-8]. A recent study carried out in Goa showed that one out of 54 An. stephensi was positive for P. falciparum malaria infection with CSP ELISA [9]. The prevailing view has been that other anopheline species do not contribute significantly to malaria transmission along the Western Coast, including Goa. In addition to An. stephensi in urban areas, Goa also has at least two other recognized rural malaria vectors, $A n$. culicifacies and An. fluviatilis [8, 10]. Anopheles culicifacies is found in low densities in the sub-coastal belt of Goa where it breeds in irrigation channels, ponds and rice paddies and An. fluviatilis is abundant in the eastern hilly regions of the state where it breeds in stagnant waters in streams and paddy fields $[8,10]$. There have been reports of $A n$. dirus in forested hinterlands of Goa, but it has not been extensively studied for its role in malaria transmission [11].

The present study involved a broad and unbiased reassessment of vectorial capacity of all significant Anopheles mosquitoes in urban Goa. This was motivated, in part, by the MESA-ICEMR hypothesis that parasites and mosquitoes may change their relationships as each comes under increasing pressure from malaria control programs $[13,14]$. Other basic science studies show that parasite populations have powerful strategies to select for beneficial changes in their haploid genome without collateral damage $[12,14,15]$. While this has previously been of interest with respect to acquisition of resistance to anti-malarials, it is possible that interactions between parasites and vectors may also be fluid. Unproductive interactions between human malaria parasites and nonvector anophelines may evolve so that human malaria parasites develop successfully in Anopheles mosquitoes not suspected to be productive hosts [16]. Continual broad investigation into the role of local anopheline species in malaria transmission areas was, thus, considered important.

Here, nested PCR was employed and both Plasmodium falciparum and $P$. vivax were detected in the salivary glands and guts of wild anopheline mosquitoes collected from Goa. The results show that anophelines other than $A n$. stephensi may participate in the propagation of human malaria in urban Goa and that parasites may exploit multiple vectors to maintain perennial transmission in Goa. The findings and this particular open-ended approach may have important implications for vector control strategies in urban India, particularly in Goa.

\section{Methods}

\section{Study area and time}

Goa, a state covering a geographical area of $3702 \mathrm{~km}^{2}$, is situated on the West Coast of India. It has a population of 1.5 million residing in two districts (North and South Goa) [8]. Construction sites located in Panjim, Candolim, Porvorim (North Goa) and Margao (South Goa) were identified as focal points for the malaria transmission study based on data received from Goa Directorate of Health Services, local Urban and Primary Health Centres, and malaria patient data from MESAICEMR operations at Goa Medical College and Hospital. Such targeted deployment of CDC traps maximised the possibility of capturing malaria vectors within active transmission zones. This paper analyses the human and bovine blood meal and the presence of human Plasmodia in the mosquitoes collected from May 2013-April 2015 in Goa.

\section{Mosquito collection}

CDC traps (John W. Hock, USA) with UV lights and $6 \mathrm{~V}$ batteries were used for trapping mosquitoes. Verbal informed consent was obtained from construction-site engineers and from house owners prior to trap deployment. People residing around the collection sites were informed of the study and they helped protect the traps from disturbance. Traps were hung inside labourer's shelters at $6 \mathrm{pm}$ and collected at $9 \mathrm{am}$ the following morning, avoiding shelters where firewood was used for cooking. The shelters where collections took place were not sprayed with any insecticides.

\section{Identification and preservation of mosquitoes}

Following deployment and recovery of traps, the mouth of each collection bag was secured to prevent escape of mosquitoes. The bags were separated from trap machines and transported to the NIMR-Goa laboratory with care to avoid damage to the mosquitoes. 
Back at the NIMR-Goa lab, the freshly collected mosquitoes were anesthetized with diethyl ether and identified using standard morpho-taxonomic keys [17, 18]. Morphological features used for identification were head, proboscis, thorax, legs, wings and palpi. The mosquitoes were individually placed in $1.5 \mathrm{~mL}$ microfuge tubes. The tubes were labelled with specific codes, sealed and placed in separate boxes designated to capture information on origin of the mosquito (including the time, place, and exact trap they came in). The samples were preserved at $-80^{\circ} \mathrm{C}$ for further analysis.

\section{DNA extraction}

Mosquitoes collected from May to July 2013 were not separated prior to DNA extraction. The rest of the mosquitoes were dissected into two parts, head/thorax $(\mathrm{H})$ and abdomen (A) by making a sharp cut between the thorax and abdomen. The legs and wings were detached from the main body and stored separately at $-80{ }^{\circ} \mathrm{C}$. Genomic DNA from whole mosquitoes or individual parts $(\mathrm{H}$ and $\mathrm{A})$ of each anopheline mosquito was extracted using QIAamp DNA Mini Kits (Qiagen, Germany). Isolated DNA, eluted in $100 \mu \mathrm{L}$ nuclease free water (Ambion) was then stored at $-80{ }^{\circ} \mathrm{C}$ for further use. DNA extracted from individual head and abdomen parts was used as the template for the PCR reaction, except for mosquitoes collected from May to July 2013. In these cases, DNA extracted from the whole mosquito was used as a template.

\section{Blood meal analysis}

To determine the potential anthropophagic nature of the mosquitoes, abdomens were screened for the presence of human and bovine blood by PCR using specific primers derived from ribosomal RNA intergenic spacer sequence of Homo sapiens and mitochondrial DNA (mtDNA) of Bos taurus respectively (Table 1). The PCR conditions were: initial denaturation at $95{ }^{\circ} \mathrm{C}$ for $4 \mathrm{~min}$ followed by 35 cycles of denaturation at $95^{\circ} \mathrm{C}$ for $30 \mathrm{~s}$, annealing at $50{ }^{\circ} \mathrm{C}$ for $30 \mathrm{~s}$, extension at $72{ }^{\circ} \mathrm{C}$ for $1 \mathrm{~min}$ and final extension at $72{ }^{\circ} \mathrm{C}$ for $8 \mathrm{~min}$ [19]. Anopheles stephensi and An. subpictus were also screened for bovine blood using specific primers by PCR as described by Corona et al. [20]. The PCR conditions were: initial denaturation at $95{ }^{\circ} \mathrm{C}$ for $2 \mathrm{~min}$; 10 cycles of denaturation at $94{ }^{\circ} \mathrm{C}$ for $1 \mathrm{~min}$, annealing at $58{ }^{\circ} \mathrm{C}$ for $1 \mathrm{~min}$, extension at $72{ }^{\circ} \mathrm{C}$ for $1 \mathrm{~min} 30 \mathrm{~s} ; 20$ cycles of denaturation at $90{ }^{\circ} \mathrm{C}$ for $1 \mathrm{~min}$, annealing at $58{ }^{\circ} \mathrm{C}$ for $1 \mathrm{~min}$, extension at $72^{\circ} \mathrm{C}$ for $1 \mathrm{~min} 30 \mathrm{~s}$; and final extension at $72{ }^{\circ} \mathrm{C}$ for $10 \mathrm{~min}$.

\section{Sibling species analysis}

The sibling species identification of An. subpictus using allele-specific PCR was carried out using the gene specific ITS2 region and confirmed by sequence analysis. The PCR conditions were: initial denaturation at $95^{\circ} \mathrm{C}$ for 4 min, followed by 35 cycles of denaturation at $95^{\circ} \mathrm{C}$ for $30 \mathrm{~s}$, annealing at $50{ }^{\circ} \mathrm{C}$ for $30 \mathrm{~s}$, extension at $72{ }^{\circ} \mathrm{C}$ for $1 \mathrm{~min}$, and final extension at $72{ }^{\circ} \mathrm{C}$ for $8 \mathrm{~min}$.

\section{Mosquito infection status}

The mosquito samples were screened for Plasmodium by PCR, initially using genus specific universal primers (28S rDNA specific universal primer set) (Table 1) [21, 22]. The following mixture was subjected to Plasmodium universal PCR: $1.5 \mu \mathrm{L}$ 10X PCR buffer $(500 \mathrm{mM}$ $\mathrm{KCl}, 200 \mathrm{mM}$ Tris- $\mathrm{HCl}), 1.0 \mu \mathrm{L}$ of $50 \mathrm{mM} \mathrm{MgCl}{ }_{2}, 2.5 \mu \mathrm{L}$ of $2.5 \mathrm{mM}$ dNTPs each (GeNei, Bangalore), $0.5 \mu \mathrm{L}$ oligonucleotide primers (Eurofins Genomics India Pvt Ltd) $20 \mathrm{pM} / \mu \mathrm{L}$ each, $0.5 \mu \mathrm{L}$ (5 units $/ \mu \mathrm{L}$ ) of Taq polymerase (Invitrogen), $3.5 \mu \mathrm{L}$ of nuclease free water (Ambion) and $15 \mu \mathrm{L}$ of template DNA in a final volume of $25 \mu \mathrm{L}$. The PCR conditions were set as follows: initial denaturation at $94{ }^{\circ} \mathrm{C}$ for $5 \mathrm{~min}$ followed by 40 cycles of denaturation

Table 1 Primers for detection of human blood, bovine blood and malaria parasites

\begin{tabular}{|c|c|c|c|c|c|}
\hline Species & $\begin{array}{l}\text { Target } \\
\text { gene }\end{array}$ & $\begin{array}{l}\text { Primer } \\
\text { name }\end{array}$ & Sequence $\left(5^{\prime}-3^{\prime}\right)$ & $\begin{array}{l}\text { PCR product } \\
\text { size (bp) }\end{array}$ & References \\
\hline \multirow[t]{2}{*}{ Homo sapiens (human) } & rDNA & HUM1 & CGAGAGTTC//TCTGGAAGAATTGA & 519 & Mohanty et al. 2007 [16] \\
\hline & & HUM2 & TGATAGCCTGGAAGTGACAAAAT & & \\
\hline \multirow[t]{2}{*}{ Bovine Bos taurus } & mtDNA & B1 & CATCATAGCAATTGCCATAGTCC & 165 & Corona et al. 2007 [20] \\
\hline & & B2 & GTACTAGTAGTATTAGAGCTAGAATTAG & & \\
\hline \multirow[t]{2}{*}{ Plasmodium (genus-wide) } & $18 \mathrm{~S}$ rRNA & rPLU5 & CCTGTTGTTGCCTTAAACTTC & 1100 & Johnston et al. 2006 [18] \\
\hline & & rPLU6 & TTAAAATTGTTGCAGTTAAAACG & & \\
\hline \multirow[t]{2}{*}{ P. falciparum (species specific) } & $18 \mathrm{~S}$ rRNA & rFAL1 & TTAAACTGGTTTGGGAAAACCAAATATATT & 205 & \\
\hline & & rFAL2 & ACACAATGAACTCAATCATGACTACCCGTC & & \\
\hline \multirow[t]{2}{*}{ P. vivax (species specific) } & $18 \mathrm{~S}$ rRNA & rVIV1 & CGCTTCTAGCTTAATCCACATAACTGATAC & 120 & \\
\hline & & rVIV2 & ACTTCCAAGCCGAAGCAAAGAAAGTCCTTA & & \\
\hline
\end{tabular}


at $94{ }^{\circ} \mathrm{C}$ for $30 \mathrm{~s}$, annealing at $55^{\circ} \mathrm{C}$ for $1 \mathrm{~min}$, extension at $72{ }^{\circ} \mathrm{C}$ for $2 \mathrm{~min}$, and final extension at $72{ }^{\circ} \mathrm{C}$ for $5 \mathrm{~min}$.

\section{Species-specific nested PCR}

In order to identify the species of Plasmodium in the infected mosquitoes, the initial amplified PCR product was generated using genus specific primers. This was then purified using Qiagen PCR purification kits and subjected to nested PCR using species specific primers [19, $21,22]$. Nested PCR was performed using the following mixture: $2.0 \mu \mathrm{L}$ 10X PCR buffer $(500 \mathrm{mM} \mathrm{KCl,} 200 \mathrm{mM}$ Tris- $\mathrm{HCl}), 1.0 \mu \mathrm{L}\left(50 \mathrm{mM} \mathrm{MgCl}{ }_{2}\right), 2.0 \mu \mathrm{L}(2.5 \mathrm{mM}$ of each dNTPs), $0.5 \mu \mathrm{L}$ of each primer $(20 \mathrm{pM} / \mu \mathrm{L}), 0.5 \mu \mathrm{L}$ (5 units $/ \mu \mathrm{L}$ ) of Taq polymerase, $8.5 \mu \mathrm{L}$ of nuclease free water and $10 \mu \mathrm{L}$ of PCR product in a total volume of $25 \mu \mathrm{L}$. The PCR conditions were: initial denaturation at $94{ }^{\circ} \mathrm{C}$ for $5 \mathrm{~min}$ followed by 40 cycles of denaturation at $94{ }^{\circ} \mathrm{C}$ for $1 \mathrm{~min}$, annealing at $55^{\circ} \mathrm{C}$ for $2 \mathrm{~min}$, extension at $72{ }^{\circ} \mathrm{C}$ for $2 \mathrm{~min}$, and final extension at $72{ }^{\circ} \mathrm{C}$ for $5 \mathrm{~min}$.

\section{Data and sample management}

REDCap electronic data management tools were utilized to record all information related to trap placement, collection and mosquito identification [23]. A FreezerPro database was used to manage mosquito and mosquito derivative storage. Data recorded in both systems were available to MESA-ICEMR partner labs in both India and the USA in real-time.

\section{Results}

\section{Anophelines collected with CDC traps}

A broad and unbiased approach was taken to determine which anopheline species in Goa may currently be transmitting human malaria. In all 23,782 mosquitoes belonging to 27 species were collected including 16,201 females and 7586 males. A total of 1375 anopheline mosquito specimens were caught in 1036 traps deployed during the study period. This collection included ten Anopheles species. One of the two dominant anopheline species was the well-studied urban and semi-urban vector An. stephensi (334, $24.3 \%)$. Another abundant vector in the traps was An. subpictus (501, 36.4\%), actually out numbering $A n$. stephensi. Together, the two species constituted $60.7 \%$ of the total anophelines trapped. There were eight other less abundant anopheline mosquito species in the traps, including 363 An. jamesii (26.4 \%), 66 An. vagus (4.8\%), 57 An. annularis (4.1\%), 36 An. nigerrimus (2.6 \%), 9 An. barbirostris (0.6\%), 7 An. tessellates (0.5\%), and 1 each of An. umbrosus and An. karwari.

\section{Seasonality of the dominant anophelines}

Not only were the absolute numbers of captured $A n$. subpictus higher than those of An. stephensi, but $A n$. subpictus showed a wider annual prevalence. As shown in Fig. 1a (red line), An. subpictus mosquitoes were captured in high numbers from May to July (117/501, $23.3 \%)$, but prevalence continued later including a prominent peak between December and April (334/501, $66.7 \%)$. For reference, the rainier months in Goa are from May to October and the dry period is from November to April (Fig. 1b, green bars). As expected and as shown in Fig. 1a (blue line), the conventional vector $A n$. stephensi collections were most abundant during the monsoon months of May to October (226/334, 67.6\%), but the numbers of An. stephensi decreased during the drier months with the 6 months of November to April yielding 108 An. stephensi (32.4\%).

\section{Blood meal analysis of the anophelines}

It was important to test whether An. subpictus, as expected for An. stephensi, was biting human hosts. Indeed, when tested for human blood with PCR (Fig. 2), the two most prevalent Anopheles species were positive for human blood at comparable frequencies.

Out of 334 An. stephensi, 100 were positive for human blood (29.9\%), but none for bovine blood. Of these, $15.4 \%$ An. stephensi assayed were positive for human blood during the monsoon phase (May-October) and $14.5 \%$ were positive during the dry period (NovemberApril), showing no seasonal variation. Out of $501 A n$. subpictus, 135 were positive for human blood (26.9 \%) and only six were positive for bovine blood (1.2\%). In contrast with An. stephensi, $2.4 \%$ An. subpictus assayed were positive for human blood during the monsoon phase and $24.1 \%$ were positive during the dry period, showing significant seasonality.

Three additional anopheline species were positive for human blood: $80 \mathrm{An}$. jamesii (21.9\%), 15 An. annularis (25.9\%), and 6 An. nigerrimus (17.1\%). None of the remaining five Anopheles species tested positive for human blood.

\section{Plasmodium infections}

To determine which anophelines in the collection harboured human malaria parasites, diagnostic PCR was conducted on each of the anopheline mosquitoes. In the case of An. subpictus, Plasmodium infection was seen in $2.8 \%(14 / 501)$ of specimens as revealed by PCR amplification of a 1100 bp DNA fragment using Plasmodium specific universal primers (Fig. 3). In addition, nested PCR was used to identify the species of Plasmodium causing infection (Fig. 4). Out of these 14 An. subpictus positive for the Plasmodium genus, two (0.6\%) showed $P$. vivax mono-infection, six (1.2 \%) showed $P$. falciparum mono-infection, and another six (1.2\%) harboured a mixture of $P$. vivax and $P$. falciparum confirmed by 

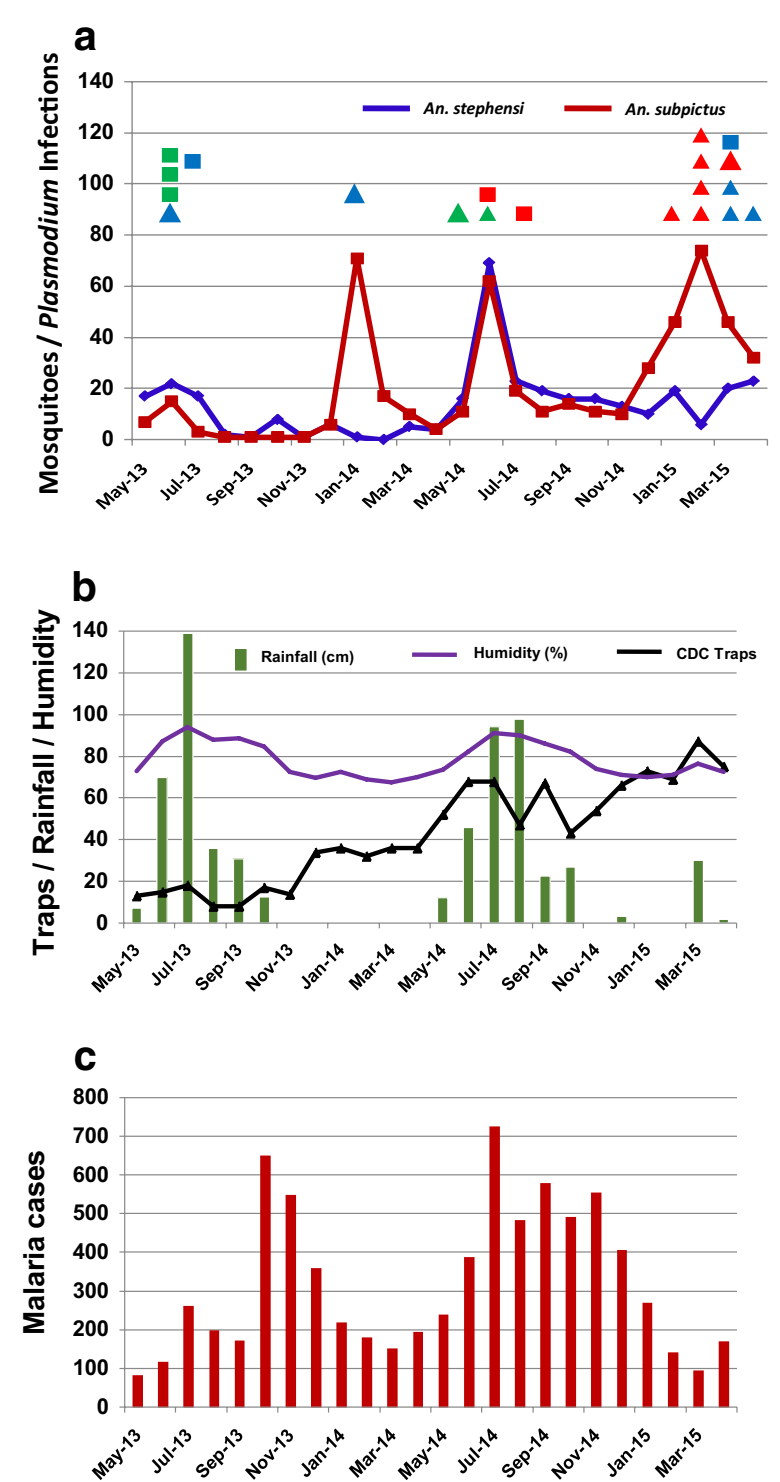

Fig. 1 Relationship between vector buildup, infected mosquitoes, rainfall in Goa, and numbers of malaria patient cases in Goa. a Anopheles stephensi and Anopheles subpictus prevalence from May 2013 to April 2015 (blue and red lines, respectively) and times of mosquito Plasmodium infections from May 2013 to April 2015 (squares and triangles above the lines). Each spot depicts one Plasmodium infection/ mosquito in different months. The colour key is as follows: Blue square: An. stephensi $(P v+P f)$, Green square: An. stephensi $(P v)$, Red square: An. stephensi (Pf), Blue triangle: An. subpictus $(P v+P f)$, Green triangle: An subpictus (Pv), Red triangle: An. subpictus (Pf). b Seasonal variation in traps placed (purple line with triangles), rainfall (green bars), humidity (plain purple line). The scale on the left applies to all three measurements (number of traps, rainfall in $\mathrm{cm}$, and humidity in \% value). c Annual distribution of malaria cases at clinics and hospitals in Goa

nested PCR (Table 2). The infectivity rate based on salivary gland positivity in An. subpictus (0.6 \%) was comparable to that of An. stephensi.
For comparison, Plasmodium infection was seen in $2.1 \%(7 / 334)$ of the traditional vector An. stephensi as revealed by PCR amplification of an 1100 bp DNA fragment using Plasmodium specific universal primers (Fig. 3). In addition, three out of the seven infected $A n$. stephensi were positive for $P$. vivax alone (120 bp amplicon), two (0.6 \%) had P. falciparum alone (205 bp band size) and another two (0.6\%) contained both $P$. vivax and P. falciparum (Table 2; Fig. 4). Finally, anthropophily of the two vectors that were positive for human malaria parasites were cross-checked. Seven of the 14 Plasmodium positive An. subpictus also showed a positive reaction for human blood as did five of the seven An. stephensi positive for Plasmodium.

A preliminary study using allele-specific PCR suggests that both sibling species A and B of An. subpictus occur in equal proportions. Three An. subpictus sibling species 'B' were Plasmodium positive in the salivary glands, suggesting a role in malaria transmission in Goa. The role of other An. subpictus sibling species in malaria transmission needs to be further investigated.

\section{Temporal distribution of vector infections in urban Goa}

The time frames for Anopheles species with $P$. falciparum and $P$. vivax infections allowed first glimpses of when each mosquito species was most active at transmitting malaria. The conventional vector, An. stephensi, was most active as a vector from May to July. Unlike An. stephensi, An. subpictus were found positive for malaria parasites from December to April as well as May to July (Table 3; Fig. 1a). This may help explain ongoing malaria cases being reported during these months at local clinics and hospitals (Fig. 1c).

The seasonal analysis of anthropophagic index of these two vector species and their specimens positive for human Plasmodium showed good correlation in the case of An. subpictus. While 3/501 (0.6 \%) An. subpictus were positive for human Plasmodium species during the prerainy season, its anthropophagic index was found to be $2.8 \%$. In contrast, 121/501 (24.1\%) An. subpictus were positive for human Plasmodium species during the dry period while its infection rate was $2.2 \%$. In contrast, during the rainy season 6/334 (1.8\%) An. stephensi tested Plasmodium positive while its anthropophagic index was $14.4 \%$. In the dry period, in spite of a $15.6 \%$ human blood index, the Plasmodium infection rate was only $0.3 \%$.

\section{Geographic distribution of vector infections in urban Goa}

The presence of An. subpictus and its infectivity was not restricted to one specific part of urban Goa. In the present study, 343, 218, 124 and 150 CDC traps were placed in Panaji, Candolim, Porvorim and Margao, respectively, for a 


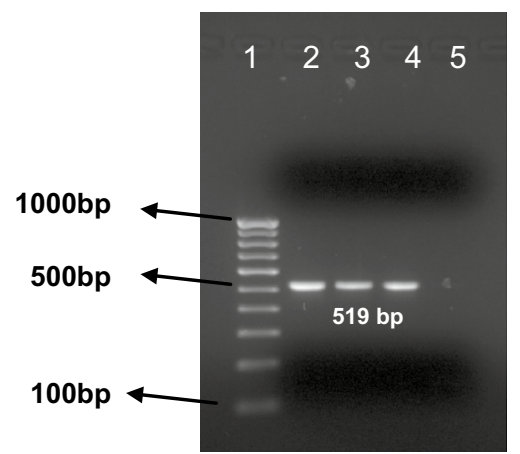

Fig. 2 Demonstration of human blood in representative mosquitoes. PCR amplification of ribosomal RNA intergenic spacer sequence (rDNA) of H. sapiens: Lane 1100 bp DNA ladder; Lane 2 and Lane 3 An. stephensi (519 bp; sample ID, ST65 and ST66); Lane 4 An. subpictus (519 bp; sample ID, SP28); Lane 5 Negative control (nuclease free water)

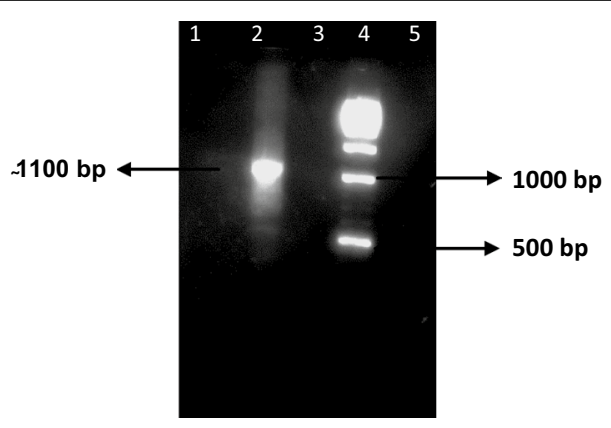

Fig. 3 Demonstration of successful PCR amplification of Plasmodium DNA using universal primers to detect an infection. Lane 1 \& 3 (Negative controls); Lane 5 negative control (Nuclease free water); Lane 2 positive (1 100 bp; Sample ID, SP328); Lane 4 (500 bp DNA ladder) total of 1036 traps (Table 4). There was an even distribution of infected versus uninfected mosquitoes in traps between the different towns. The Plasmodium infection in An. subpictus and An. stephensi, were 8 (2.3\%), 4 (1.8\%), 4 (3.2\%), and $5(3.3 \%)$, respectively, in these four locations. On average, $2.0 \%$ of the CDC traps captured infected mosquitoes.

\section{Discussion}

Traditional views of major urban malaria vectors in western India do not include An. subpictus. While An. subpictus infected with $P$. falciparum and $P$. vivax is new in Western India, and in Goa in particular, An. subpictus has been reported as a malaria vector in Sri Lanka, Eastern and Central India, Maldives and several other parts of South and South East Asia [24-31].

In the present open-ended study, CDC traps were continuously deployed in four malaria endemic towns of Goa over a period of two years. An. subpictus was found to harbour Plasmodium alongside An. stephensi in Goa. Salivary gland positivity further suggested that An. subpictus was capable of propagating both $P$. vivax and $P$. falciparum in humans in Goa. The present collection showed one of the highest reported figures for $A n$. subpictus testing positive for human blood in an urban area [28]. Furthermore, An. subpictus showed an infection rate of nearly $2.8 \%$ and an infectivity rate of $0.6 \%$ (Table 2), which is comparable to earlier findings [27]. Other known malaria vectors in non-urban and forested areas of Goa, An. culicifacies and An. fluviatilis, were not caught in CDC traps, confirming earlier findings $[6,8,9]$.

It was surprising and important to note that not only was An. subpictus the predominant anopheline mosquito, but that it also had two prevalence peaks during the year.

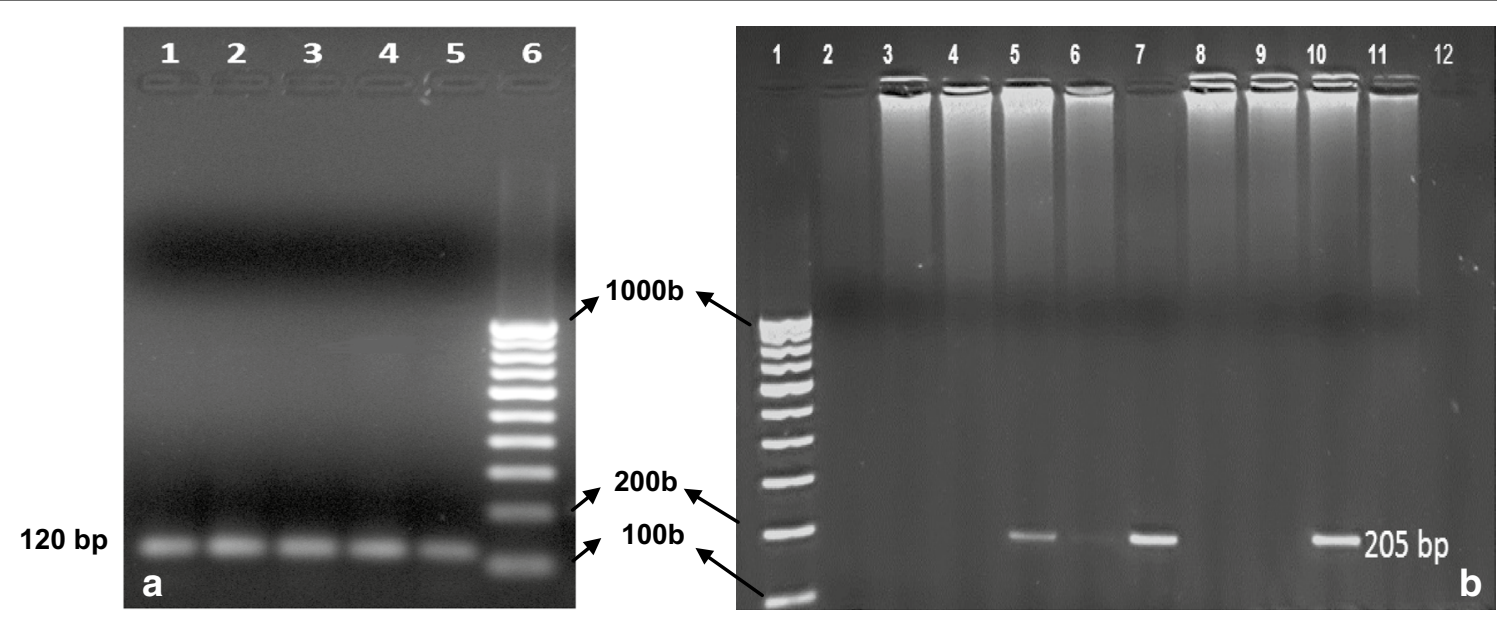

Fig. 4 Demonstration of representative nested PCR amplification to detect P. vivax (a) and P. falciparum (b): a Lane 1,2,3,4 An stephensi (Mosquito sample ID, ST24, ST31, ST32, ST54) positive for P. vivax; Lane 5 An. subpictus positive for P. vivax (SP12); Lane 6100 bp DNA ladder b Lane 1100 bp DNA ladder, Lane 2,3,4,6,8,9,11,12 (Negative, Sample ID, SP315, SP322, SP325, SP369, SP386, SP389, SP392, SP 399). Lane 5, 7 are positive for An. subpictus (SP328, SP371) and Lane 10 is positive for P. falciparum in An. stephensi (ST298) 
Table 2 Detection of Plasmodium species in Anopheles subpictus and in Anopheles stephensi

\begin{tabular}{|c|c|c|c|c|c|c|c|c|}
\hline $\begin{array}{l}\text { Vector } \\
\text { species }\end{array}$ & $\begin{array}{l}\text { No. Plasmodium } \\
\text { + ve/assayed }\end{array}$ & $\begin{array}{l}\text { Parts of mosquito } \\
\text { tested }\end{array}$ & $\begin{array}{l}\text { Number } \\
\text { tested }\end{array}$ & Only $P v$ & Only Pf & $P v+P f$ & Total positive & $\begin{array}{l}\text { Infection/infectivity } \\
\text { rate (\%) }\end{array}$ \\
\hline \multirow[t]{3}{*}{ An. subpictus } & $14 / 501$ & Whole & 25 & 0 & 0 & 1 & 1 & $2.8^{b}$ \\
\hline & & Abdomen & 476 & 1 & 6 & $5\left(2^{\mathrm{a}}\right)$ & $12\left(2^{\mathrm{a}}\right)$ & \\
\hline & & Head & 476 & 1 & 0 & $2^{a}$ & $3\left(2^{\mathrm{a}}\right)$ & $0.6^{c}$ \\
\hline \multirow[t]{3}{*}{ An. stephensi } & $7 / 334$ & Whole & 56 & 3 & 0 & 1 & 4 & $2.1^{b}$ \\
\hline & & Abdomen & 278 & 0 & $2\left(1^{\mathrm{a}}\right)$ & $1^{\mathrm{a}}$ & $3\left(2^{\mathrm{a}}\right)$ & \\
\hline & & Head & 278 & 0 & $1^{\mathrm{a}}$ & $1^{\mathrm{a}}$ & $2^{\mathrm{a}}$ & $0.6^{c}$ \\
\hline
\end{tabular}

Pv P. vivax; Pf P. falciparum

a Indicates same mosquito tested positive for both head and abdomen hence counted once

b Indicates infection rate

c Indicates infectivity rate

Table 3 Transmission periods assessed by times of positive specimens in the CDC trap collections

\begin{tabular}{llll}
\hline Vector & P. vivax & P. falciparum & $\begin{array}{l}\text { P. vivax }+\boldsymbol{P} . \\
\text { falciparum }\end{array}$ \\
\hline An. subpictus & May 1 & January 1 & January 2 \\
& June 1 & February 4 & March 2 \\
& & March 1 & April 1 \\
& & June 1 \\
An. stephensi & June 3 & June 1 & March 1 \\
& & August 1 & July 1 \\
\hline
\end{tabular}

Anopheles subpictus showed a wider window of transmission from December to April and then again from May to July, overlapping with the An. stephensi peak transmission. It appears that the two vectors work in tandem to sustain continual malaria transmission throughout the year. Without An. subpictus, An. stephensi may not be able to sustain transmission through the drier months itself.

An interesting question is how An. subpictus is better able to propagate than An. stephensi during the dry season of December to April. While An. stephensi breeds mainly in manmade habitats in Goa such as curing waters, masonry tanks, terraces, lintels, overhead tanks and wells, An. subpictus additionally breeds in a variety of natural puddles, pools, ponds, pit wells, rice paddies and backwaters $[5,6]$. This wider choice of breeding habitat may give An. subpictus one advantage over An. stephensi. Detailed work on the south coast of Java showed the salt water sibling species ' $\mathrm{B}$ ' of An. subpictus complex positive for sporozoite infection in salivary glands [32, 33]. The fact that An. subpictus can breed in fresh water as well as salt water systems, where it can tolerate a very high degree of salinity, may have important implications for its ability to breed year round [4].

One important outcome of this study is that continual, open-ended surveys of all potential vectors of human malaria transmission can be an effective monitoring tool to guide control strategies, particularly in urban areas, and may help identify conventionally overlooked vectors.

\section{Conclusions}

The present study shows the presence of $P$. vivax and $P$. falciparum in both salivary glands and mid-guts of An. subpictus in Goa, India. The study highlights that An. subpictus is more prevalent than the recognized primary urban vector, An. stephensi in the coastal region of Goa. There is high probability that An. subpictus contributes to the propagation of malaria in urban Goa especially during the postmonsoon period when An. stephensi numbers decline. Given that An. subpictus is present throughout India and

Table 4 Anopheles subpictus and Anopheles stephensi collections and their infection status at multiple sites in Goa

\begin{tabular}{|c|c|c|c|c|c|c|c|}
\hline \multirow[t]{2}{*}{ Locality in Goa } & \multirow[t]{2}{*}{ No. of traps } & \multicolumn{3}{|c|}{ No. of Anopheles } & \multirow{2}{*}{$\begin{array}{l}\text { Mean Anopheles } \\
\text { vectors/trap }\end{array}$} & \multirow{2}{*}{$\begin{array}{l}\text { No. Anopheles } \\
\text { Plasmodium+ve (IR \%) }\end{array}$} & \multirow{2}{*}{$\begin{array}{l}\text { \% Trap } \\
\text { with infected } \\
\text { vectors }\end{array}$} \\
\hline & & stephensi & subpictus & Total & & & \\
\hline Panaji + & 328 & 142 & 201 & 343 & 1.04 & $8(2.3)$ & 2.4 \\
\hline Candolim & 245 & 85 & 133 & 218 & 0.88 & $4(1.8)$ & 1.6 \\
\hline Porvorim & 176 & 47 & 77 & 124 & 0.70 & $4(3.2)$ & 2.3 \\
\hline Margao & 287 & 60 & 90 & 150 & 0.52 & $5(3.3)$ & 1.7 \\
\hline Total & 1036 & 334 & 501 & 835 & 0.8 & $21(2.5)$ & 2.0 \\
\hline
\end{tabular}

Panaji+ Panaji and surroundings, IR combined infection rate in vectors 
Asia and can breed year-round in coastal areas, monitoring and further study of An. subpictus should be an integral part of national urban vector control measures in Asia.

\section{Abbreviations}

CDC: Centres for Disease Control and Prevention; CSP: circumsporozoite protein; DDT: dichlorodiphenyl trichloroethane; DNA: deoxynucleic acid; ELISA: enzyme linked immune sorbent assay; HBI: human blood index; ICEMR: International Centre of Excellence for Malaria Research; MESA: Malaria Evolution in South Asia; NIAID: National Institute of Allergy and Infectious Diseases; NVBDCP: National Vector Borne Diseases Control Programme; PCR: polymerase chain reaction; RNA: ribose nucleic acid; USA: United States of America; UV: ultraviolet; WHO: World Health Organization.

\section{Authors' contributions}

AM, MN, TS, SJ, RH, AS, and SK performed the experiments and analyzed the results. TS, AM, AK, LC, and PR wrote and edited the manuscript. AK, NV, LC and PR designed and administered the study. All authors read and approved the final manuscript.

\section{Author details \\ ${ }^{1}$ National Institute of Malaria Research, Field Unit, Campal, Goa, India. ${ }^{2}$ National Institute of Malaria Research (ICMR), Sector 8, Dwarka, New Delhi, India. ${ }^{3}$ Department of Chemistry, University of Washington, Seattle, WA, USA.}

\section{Acknowledgements}

This work was supported by the US NIAID MESA-ICEMR Program Project U19AI08688 (NIH) to the University of Washington, Seattle, WA, USA, and by the Government of India (Indian Council of Medical Research and the National Institute of Malaria Research). The authors thank Jennifer Maki and Suresh Kumar M. of the University of Washington, and Siddhatray Tari, Shamu Angalkurthi, Prathmesh Ghavanalkar and Chetan Dabhale, Sushma Bhinge, Pallavi Borkar, Priyanka Raikar, Hemanth Kumar, and additional support staff of NIMR. This manuscript was approved by the publication committee of NIMR and bears approval No.058/2015.

\section{Competing interests}

The authors declare that they have no competing interests.

Received: 10 December 2015 Accepted: 17 February 2016 Published online: 27 February 2016

\section{References}

1. Kumar A, Valecha N, Jain T, Dash AP. Burden of malaria in India: retrospective and prospective view. Am J Trop Med Hyg. 2007;77:69-78.

2. Murray CJ, Rosenfeld LC, Lim SS, Andrews KG, Foreman KJ, Haring D, et al. Global malaria mortality between 1980 and 2010: a systematic analysis. Lancet. 2012;379:413-31.

3. Dash AP, Valecha N, Anvikar AR, Kumar A. Malaria in India: challenges and opportunities. J Biosci. 2008;33:583-92.

4. Ramachandra Rao T. The anophelines of India. Malaria Research Centre (ICMR), Delhi India; 1984.

5. Kumar A, Sharma VP, Thavaselvam D. Malaria related to constructions in Panaji. Goa. Indian J Malariol. 1991;28:219-25.

6. Kumar A, Thavaselvam D. Breeding habitats and their contribution to Anopheles stephensi in Panaji. Indian J Malariol. 1992;29:35-40.

7. Sumodan PK, Kumar A, Yadav RS. Resting behavior and malaria vector incrimination of Anopheles stephensi in Goa. India. J Am Mosq Control Assoc. 2004;20:317-8.

8. Korgaonkar NS, Kumar A, Yadav RS, Kabadi D, Dash AP. Mosquito biting activity on humans and detection of Plasmodium falciparum infection in Anopheles stephensi in Goa, India. Indian J Med Res. 2012;135:120-6.

9. Korgaonkar NS, Kumar A, Yadav RS, Kabadi D, Dash AP. Sampling of adult mosquito vectors with Mosquito Magnet Pro in Panaji, Goa, India. J Am Mosq Control Assoc. 2008;24:604-7.
10. Borcar P, Srivastava H, Roy R, Mukherji N. Malaria eradication programme in Goa. Bull Indian Soc Malaria Other Commun Dis. 1967:4:45-54

11. Obsomer V, Defourny P, Coosemans M. The Anopheles dirus complex: spatial distribution and environmental drivers. Malar J. 2007;6:26.

12. Narayanasamy K, Chery L, Basu A, Duraisingh MT, Escalante A, Fowble J, et al. Malaria evolution in South Asia: knowledge for control and elimination. Acta Trop. 2012;121:256-66.

13. Kumar A, Chery L, Biswas C, Dubhashi N, Dutta P, Dua VK, et al. Malaria in South Asia: prevalence and control. Acta Trop. 2012;121:246-55.

14. Rathod PK, McErlean T, Lee PC. Variations in frequencies of drug resistance in Plasmodium falciparum. Proc Natl Acad Sci USA. 1997;94:9389-93.

15. Guler JL, Freeman DL, Ahyong V, Patrapuvich R, White J, Gujjar R, et al. Asexual populations of the human malaria parasite, Plasmodium falciparum, use a two-step genomic strategy to acquire accurate, beneficial DNA amplifications. PLoS Pathog. 2013;9:e1003375.

16. Molina-Cruz A, Barillas-Mury C. The remarkable journey of adaptation of the Plasmodium falciparum malaria parasite to New World anopheline mosquitoes. Mem Inst Oswaldo Cruz. 2014;109:662-7.

17. Christophers S. The Fauna of British India, including Ceylon and Burma. Diptera Family Culicidae Tribe Anophelini, vol. IV. London: Taylor \& Francis; 1933.

18. Nagpal B, Sharma V. Indian anophelines. Science Publishers, Inc. 1995.

19. Mohanty A, Kar P, Mishra K, Singh DV, Mohapatra N, Kar SK, et al. Multiplex PCR assay for the detection of Anopheles fluviatilis species complex, human host preference, and Plasmodium falciparum sporozoite presence, using a unique mosquito processing method. Am J Trop Med Hyg. 2007;76:837-43.

20. Corona B, Lleonard R, Carpio Y, Uffo O, Martínez S. PCR detection of DNA of bovine, ovine -caprine and porcine origin in feed as part of a bovine spongiform encephalopathy control program. Spanish J Agri Res. 2007;5:312-7.

21. Snounou G, Pinheiro L, Goncalves A, Fonseca L, Dias F, Brown KN, et al. The importance of sensitive detection of malaria parasites in the human and insect hosts in epidemiological studies, as shown by the analysis of field samples from Guinea Bissau. Trans R Soc Trop Med Hyg. 1993:87:649-53.

22. Johnston SP, Pieniazek NJ, Xayavong MV, Slemenda SB, Wilkins PP, da Silva AJ. PCR as a confirmatory technique for laboratory diagnosis of malaria. J Clin Microbiol. 2006;44:1087-9.

23. Harris PA, Taylor R, Thielke R, Payne J, Gonzalez N, Conde JG. Research electronic data capture (REDCap) — a metadata-driven methodology and workflow process for providing translational research informatics support. J Biomed Inform. 2009:42:377-81.

24. Roy D. The role of Anopheles subpictus Grassi as a carrier of malaria. J Mal Inst India. 1943;6:117-21.

25. Panicker K, Bai MG, Rao UB, Viswam K, Murthy US. Anopheles subpictus, vector of malaria in coastal villages of south-east India. Curr Sci. 1981;50:694-5.

26. Kulkarni SM. Feeding behaviour of anopheline mosquitoes in an area endemic for malaria in Bastar district, Madhya Pradesh. Indian J Malariol. 1987;24:163-71

27. Chandra G, Bhattacharjee I, Chatterjee S. A review on Anopheles subpictus Grassi-A biological vector. Acta Trop. 2010;115:142-54.

28. Kumari S, Parida SK, Marai N, Tripathy A, Hazra RK, Kar SK, et al. Vectorial role of Anopheles subpictus Grassi and Anopheles culicifacies Giles in Angul District, Orissa, India. Southeast Asian J Trop Med Public Health. 2009;40:713-9.

29. Amerasinghe $\mathrm{PH}$, Amerasinghe FP, Wirtz RA, Indrajith NG, Somapala W, Pereira LR, et al. Malaria transmission by Anopheles subpictus (Diptera: Culicidae) in a new irrigation project in Sri Lanka. J Med Entomol. 1992:29:577-81.

30. Surendran SN, Singh OP, Jude PJ, Ramasamy R. Genetic evidence for malaria vectors of the Anopheles sundaicus complex in Sri Lanka with morphological characteristics attributed to Anopheles subpictus species B. Malar J. 2010:9:343.

31. Surendran SN, Sarma DK, Jude PJ, Kemppainen P, Kanthakumaran N, Gajapathy $\mathrm{K}$, et al. Molecular characterization and identification of members of the Anopheles subpictus complex in Sri Lanka. Malar J. 2013;12:304.

32. Sundararaman S, Soeroto RM, Siran M. Vectors of malaria in Mid-Java. Indian J Malariol. 1957;11:321-38.

33. Rathinam KG. Studies on Anopheles subpictus complex. Ph.D. thesis. Pondicherry University India. 1992; 1-21. 